\title{
The method of strengthening the church building in terms of the planned mining exploitation
}

\author{
Lukasz Drobiec ${ }^{1, *}$ Tomasz Niemiec ${ }^{2}$, Marian $\mathrm{Kawulok}^{3}$, Leszek $\mathrm{Słowik}^{3}$, \\ and Leszek Chomacki ${ }^{3}$ \\ ${ }^{1}$ Department of Building Structures, Faculty of Civil and Environmental Engineering, Silesian \\ University of Technology, Akademicka 5, 44-100 Gliwice, Poland \\ ${ }^{2}$ MPL Katowice Sp. z o.o. , al. Roździeńskiego 188, 40-203, Katowice, Poland \\ ${ }^{3}$ ITB Building Research Institute, Building Structures, Geotechnics and Concrete Department, \\ 40-153 Katowice al. W. Korfantego 191, Poland
}

\begin{abstract}
This article describes the method of strengthening a church building in Ruda Śląska against predicted effects of mining exploitation. The building had been already exposed to effects of 22 mining incidents which significantly damaged walls and vaults. Therefore, it was decided to strengthen the building before new exploitation works. Strengthening works included longitudinal walls support with the tendon system built over the vault support. Additionally, ribs were strengthened by suspending them to new reinforced concrete ribs placed over the existing ones. And precast concrete cube elements were used in new ribs.
\end{abstract}

\section{Introduction}

Building structures in mining areas are exposed to additional load from ground deformation caused by mining exploitation. Thus, designing new buildings or strengthening the existing ones should include the structure protection adjusted to carry possible forced displacements, deformations and ground vibrations [1,2].

In practice, mining conditions of the building in the area sensitive to mining deformations is determined by its location in terms of the mining front or its location in the fixed basin, and the occurrence of any possible discontinuous deformations. It is also the consequence of exploiting further layers of the same coal seam. Thus, the building is exposed to repeated impacts of ground deformations of the similar type, direction and strength. The effect of overlapping exploitation works in different seams performed in different direction is also significant in terms of their impact on the surface and edges of the fixed basin, which results in twisting of the construction.

This article describes the design and works on strengthening the body of historic church of St. Wawrzyniec in Ruda Śląska (Wirek district). In the past this building was exposed to numerous mining exploitation works and underwent many repairs [3]. Another exploitation works has been planned to be performed directly under the building at the turn of 2018 and 2019. Thus, the additional strengthening of the church is required.

\footnotetext{
${ }^{*}$ Corresponding author: lukasz.drobiec@polsl.pl
} 


\section{Description of the building}

The church was built in a neo-Gothic style in years 1907-1909 according to the design of Ludwig Schneider - an architect from Wrocław. Construction works were supervised by a masonry master Neumann from Bytom. The church was consecrated by Cardinal Adolf Bertram in 1918. The building was furnished in a neo-Gothic style. Stain-glass windows were made by Karl Lersch from Düsseldorf in 1908. The church building was entered into the listed building register (No. A/9/99) in 1999.

It is built from ceramic bricks and calcareous mortar. The aisle and transept cover is in the form of cloister vaults. It has a timber queen post truss. The roof is covered with tiles. The church tower is ca. $60.0 \mathrm{~m}$ high and has dimensions $11.7 \times 22.0 \mathrm{~m}$. Maximum dimensions of the building plan at the ground level are $32.0 \times 54.0 \mathrm{~m}$. Fig. 1 shows the side elevation. The facade with the tower is illustrated in Fig. 2, and the church plan is in Fig. 3.

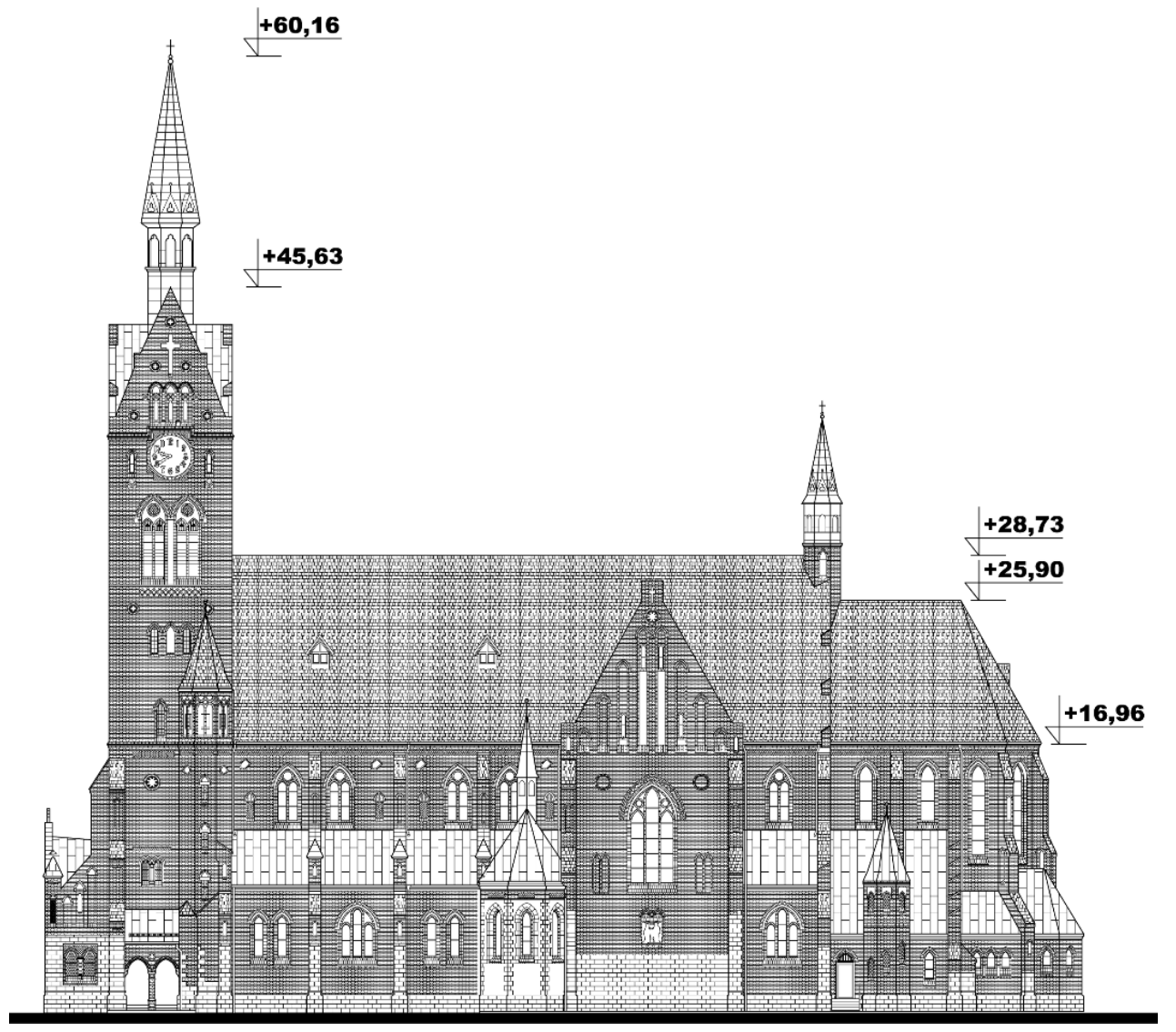

Fig. 1. Side elevation. 
a)

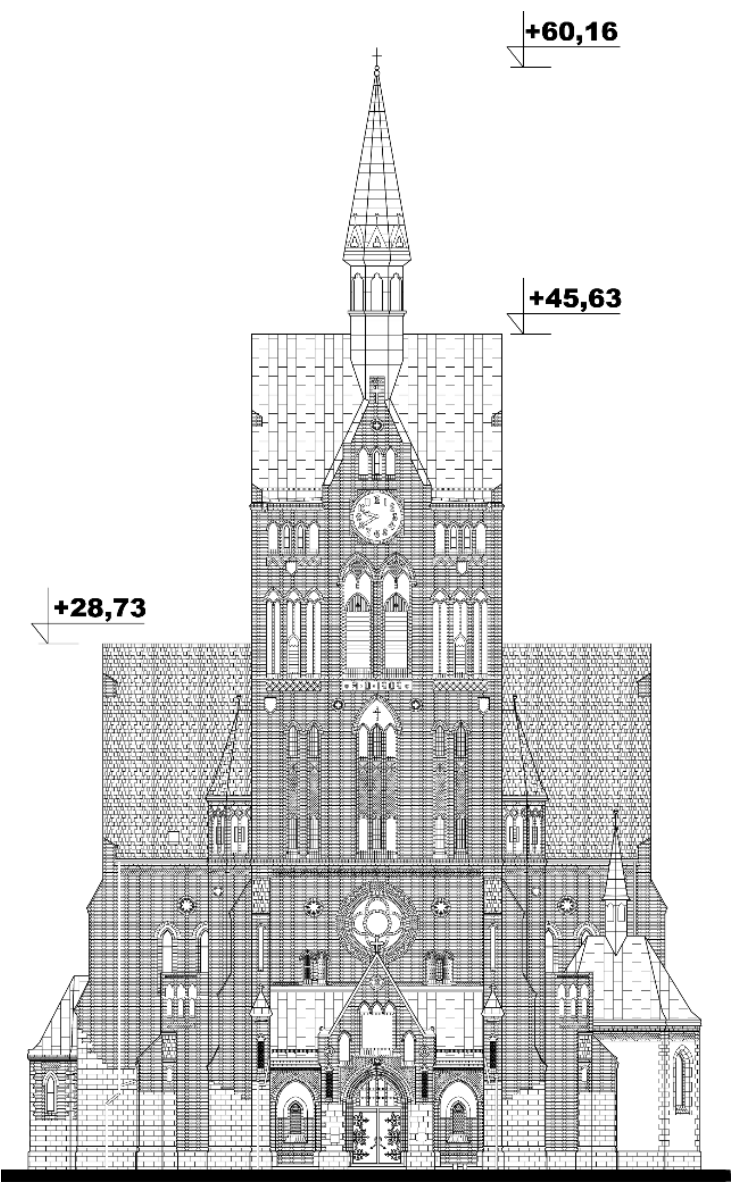

b)

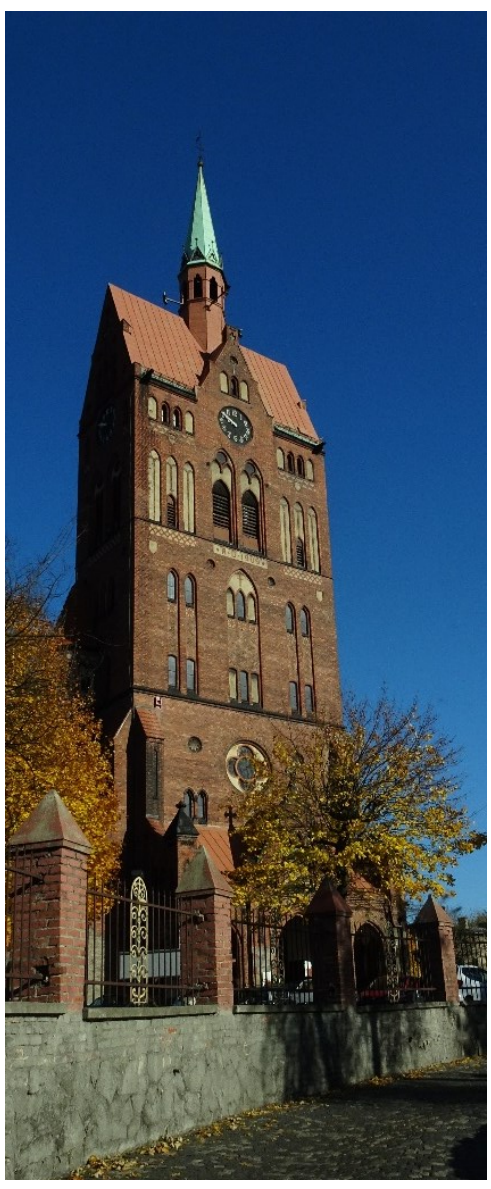

Fig. 2. a) facade view, b) facade photo.

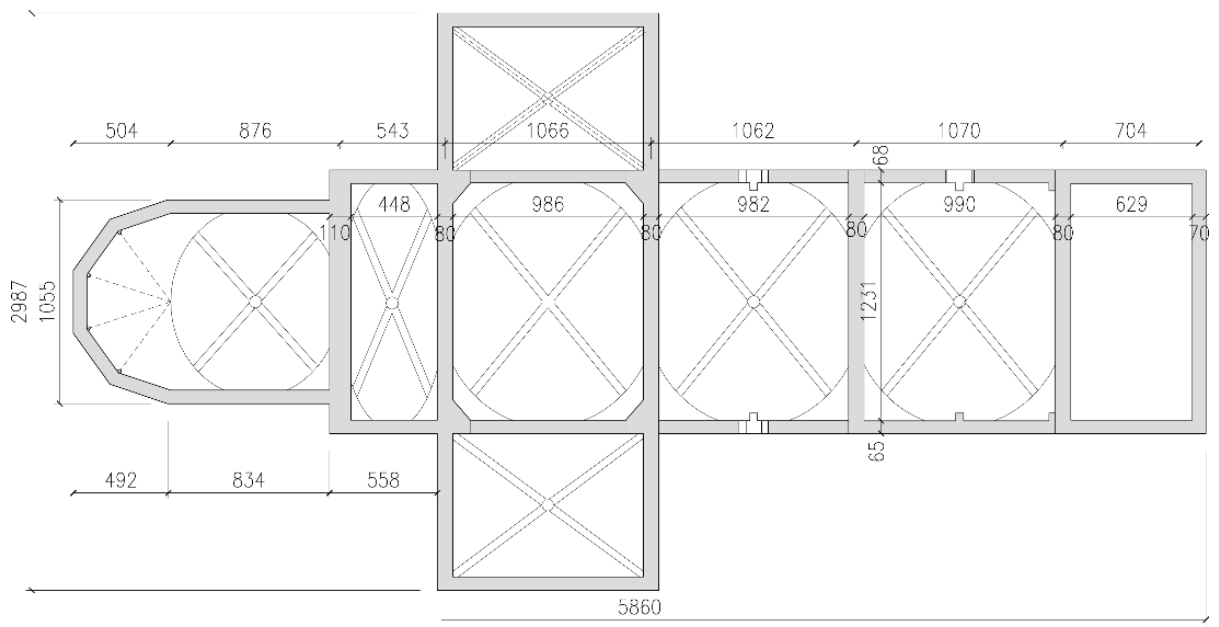

Fig. 3. The church plan above the vault level. 


\section{Performed strengthening and repairing works}

The building has been exposed to effects of exploiting 22 seams since 1930 [3]. In the 1970s, a reinforced concrete plate was performed around the church at the ground level according to the concept of prof. Ledwoń [4]. Further works just focused on eliminating effects of other exploitation works. Wall repairs were the most common. They included crack filling, rebricking, crack stitching with the helical reinforcement, and injections of cracks in vaults. In 2017, walls and extreme vaults from the tower side were considerably damaged by the tower tilting from the building. The reinforced concrete band was cracked and damaged (failure of the reinforcement continuity). Wall cracks were stitched with reinforcement and rebricked (Fig. 4a). The vault was repaired by injecting cracks and strengthening ribs from the upper side with FRCM (fiber reinforced cementitious matrix) - a carbon fibre grid embedded into the cementitious matrix. And the reinforced concrete plate was broken down. The reinforcement became again continuous by welding new inserts and recementing. More information about this repair is described in the paper [3].

a)

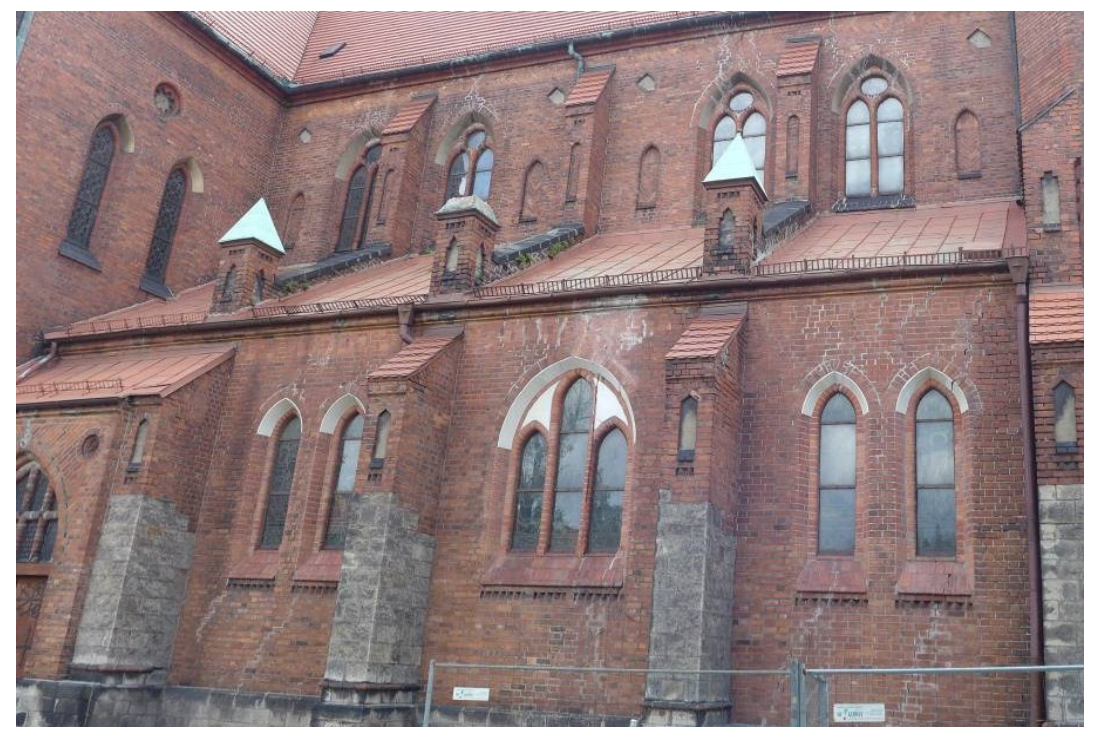

b)

c)
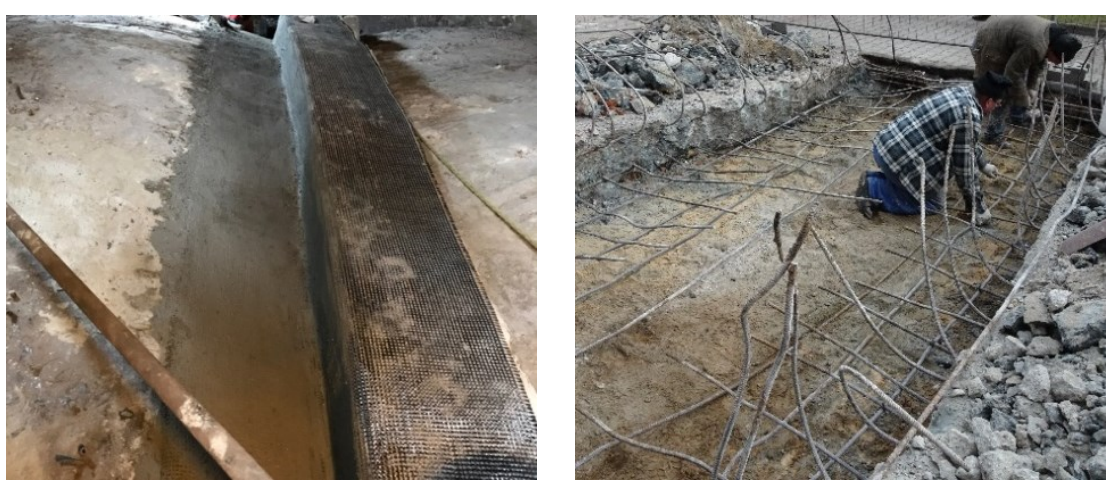

Fig. 4. Strengthening works executed in 2017: a) remarks after repairing cracks in the elevation, b) strengthening ribs in the vault with FRCM system, c) repair of reinforced concrete plate. 


\section{Plans of further exploitation}

In 2018, plans were made for another exploitation directly under the church building. The predicted minimum radius of curvature was $R_{\min }=+37 \mathrm{~km}$ and the ground slope was $T_{\max }=6 \%$. Regarding the direction of exploitation works, the church tower will be affected at first and will start to tilt towards the south (its deflection will increase). However, the main building will be exposed to effects that will reduce its deflection towards the north. Taking into account the range of damage observed in 2017 and the consequent significant loss in the structure rigidity, a decision was made to strengthen the building. Therefore, works on elaborating the strengthening concept began. The anchorage of the tower and the church with longitudinal steel tie rods above the support level of vaults was proposed [3].

\section{Design of strengthening}

In comparison to the conception described in the paper [3], this plan assumed tie rods divided into smaller segments and additional strengthening of ribs in vaults. The strengthening plan included steel tie rods of $40 \mathrm{~m}$ in length. Their elastic expansions was ca. $40 \mathrm{~mm}$. Their proper functioning requires regular inspections at short intervals and corrections of their tension with a torque wrench. To facilitate the service of the performed strengthening, it was decided to divide tie rods into smaller segments and anchorage them at walls of self-supporting arch at the spacing of $11.4 \mathrm{~m}$ on average. Expansion of such tie rods is $\Delta l=l \cdot \varepsilon=11.4 \mathrm{~m} \cdot\left(215 \mathrm{~N} / \mathrm{mm}^{2}\right) / 210 \mathrm{kN} / \mathrm{mm}^{2} \approx 14 \mathrm{~mm}$. It is still a high value and the tensions will require further corrections with stretching screws as effects will be observed.

The main aisle was designed to be strengthened with tie rods from the attic inside, while the presbytery was to be strengthened from the external side of the church as effective anchorage was impossible. Strengthening of the main aisle included two steel bars with a diameter of $25 \mathrm{~mm}$ and the strength of $250 \mathrm{~N} / \mathrm{mm}^{2}$, and the presbytery strengthening included one bar with a diameter of $22 \mathrm{~mm}$, made from the same type of steel.

The additional strengthening of ribs was proposed to protect vaults against extreme cracks. The initial idea suggested the application of FRCM system in the extreme vault from the side of the tower (see Fig. 4b). However, this solution was too expensive and finally this type of strengthening was not used. In the end, ribs will be strengthened as arched reinforced concrete structures from the top, to which ribs will be attached. The assumed section of strengthening is $16 \times 16 \mathrm{~cm}$, which is significantly smaller than the width of a brick rib in the vault. Its purpose it to control conditions (and possible cracks) of brick ribs from the top and minimize the impact of strengthening on water vapour level in the rib. The existing rib and the new reinforced concrete rib are to be connected with a stainless steels anchor having a diameter of $12 \mathrm{~mm}$, bonded into the existing anchor and through the tacking layer. New ribs were reinforced with 4 rebars having a diameter of $10 \mathrm{~mm}$, made of steel with high ductility and high resistance (class C, $500 \mathrm{~N} / \mathrm{mm}^{2}$ ). Total continuity of the reinforcement and rebar connection by welding were assumed.

However, concreting even so small ribs in the church vaults may be troublesome, particularly during the transport of concrete mix over large distance and at height. To eliminate these difficulties, ribs were expected to be partially composed of precast units in the form of cubes with openings for rebars and intentionally prepared surface to anchorage normal concrete. A view and dimensions of the cube are shown in Fig. 5. Cubes are assumed to be arranged in the axial spacing every $32 \mathrm{~cm}$, and space between cubes will be filled with normal concrete. Also, anchorage at the existing rib will be performed in these zones. 
a)

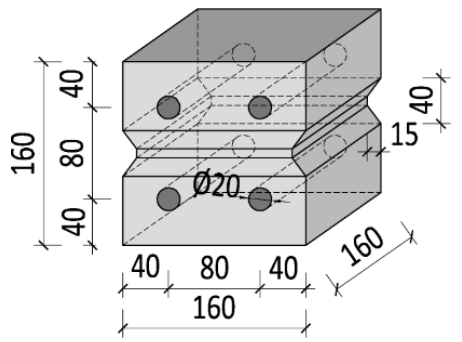

b)

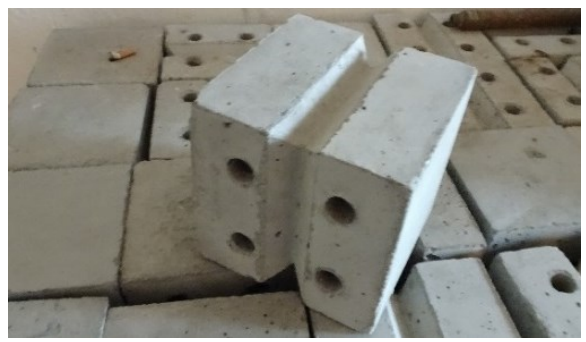

Fig. 5. Precast cube to strengthen the rib: a) dimensions, b) a view.

Computational analysis of the planned strengthening of ribs was performed. Ribs of the church vaults were modelled in the FEM software. The analysis was made for existing conditions with the load exerted by self-weight and displacement resulting from the predicted impact of exploitation and conditions with additional strengthening in the form reinforced concrete ribs, for which self-weight load and displacement resulting from the predicted impact of exploitation were assumed. Constant load to the rib was distributed in accordance with geometry principles of load division (Fig. 6). Thus, non-uniform loading became necessary (Fig. 7). Loading with displacement was uniformly distributed to vaults due to executed tie rods (Fig. 8).
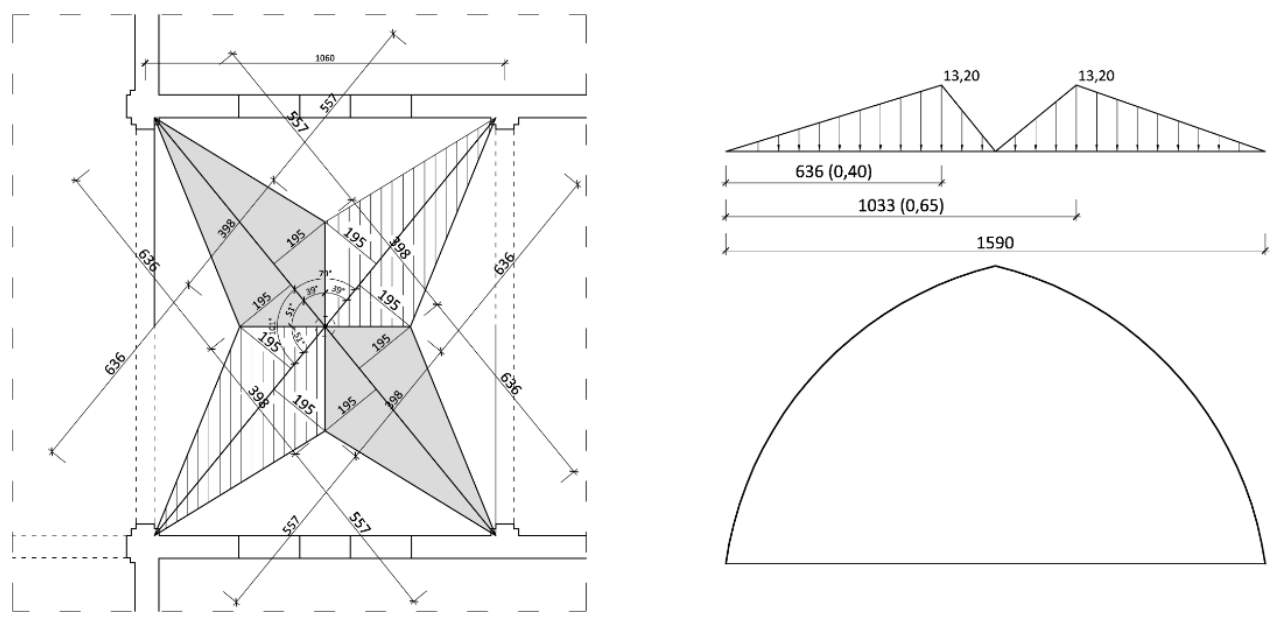

Fig. 6. Load distribution from squinch to ribs: the plan and the cross-section.

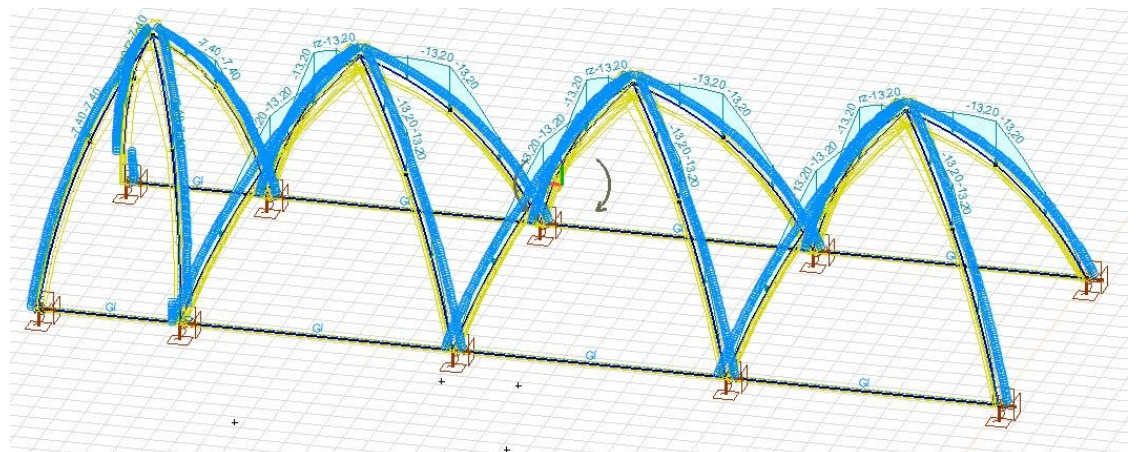

Fig. 7. Constant weight load. 


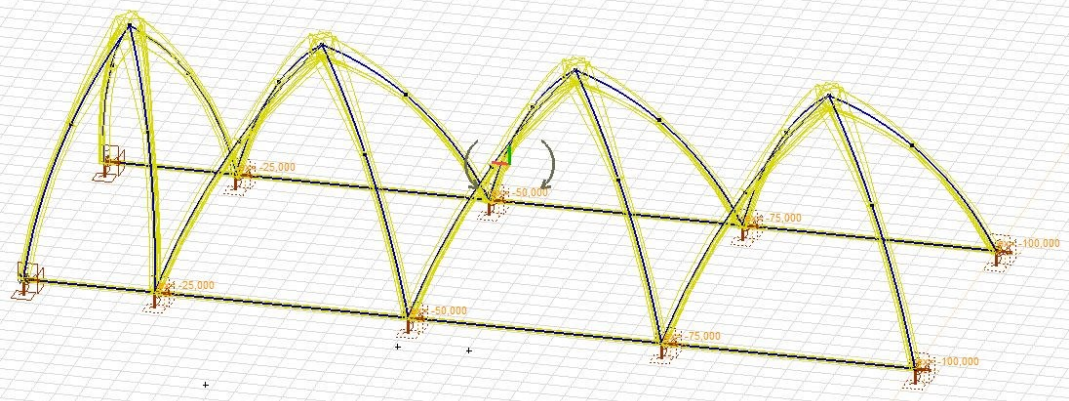

Fig. 8. Loading with displacement.

Fig. 9 presents computational results. Under existing conditions, maximum tensile stress is $3.59 \mathrm{~N} / \mathrm{mm}^{2}$ (Fig. 9a), and drop to $1.62 \mathrm{~N} / \mathrm{mm}^{2}$ after strengthening works. Tensile strength of the masonry [5] can be assumed equal to its bending strength from the plane at failure to the plane perpendicular to bed joints, that is $f_{\mathrm{t}}=f_{\mathrm{xk} 1}=0.1 \mathrm{~N} / \mathrm{mm}^{2}$. Therefore, significant cracking of vaults will be observed in case of no strengthening. Otherwise, stress at ribs will be reduced by $50 \%$ and will be carried by strengthening elements. However, tensile stress will be still higher than tensile strength of the masonry. It means that designed strengthening should provide safety of the building, but cannot guarantee the lack of cracks in vaults.

a)

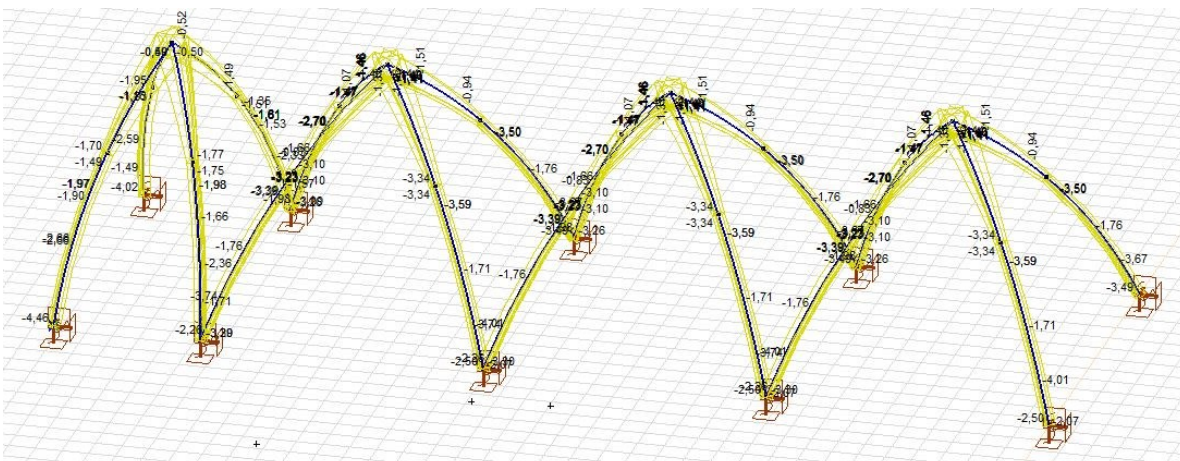

b)

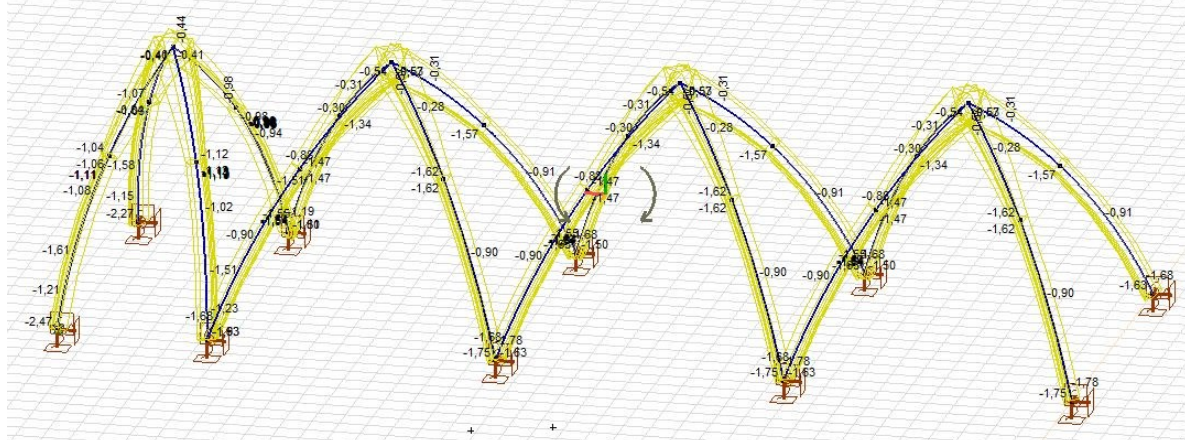

Fig. 9. Tensile stresses in: a) the model without strengthening, b) the strengthened model.

Fig. 10 presents the designed method of strengthening the church body with tie rods, and the method of rib strengthening is illustrated in Fig. 11. 


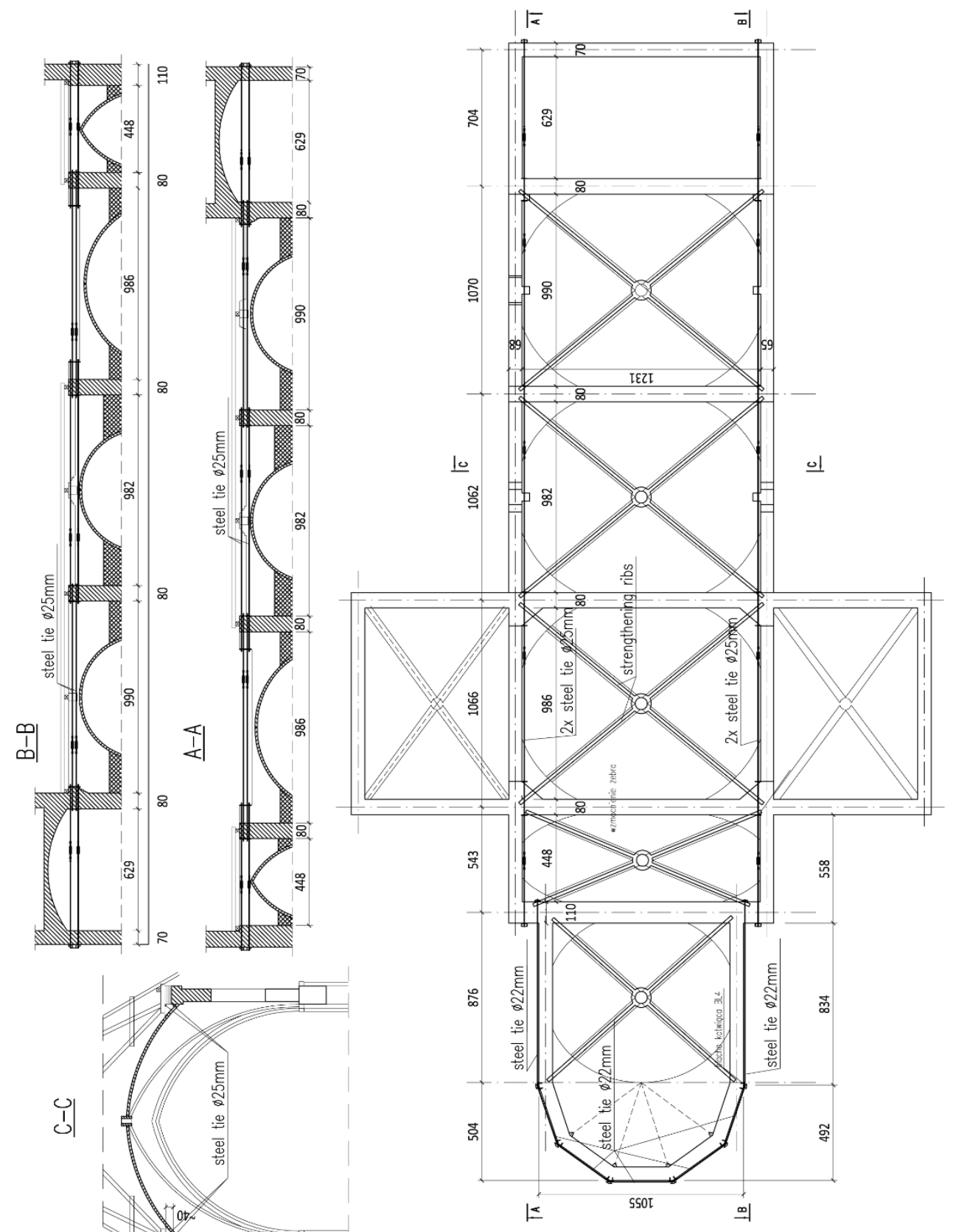

Fig. 10. Strengthening the church body with tie rods. 

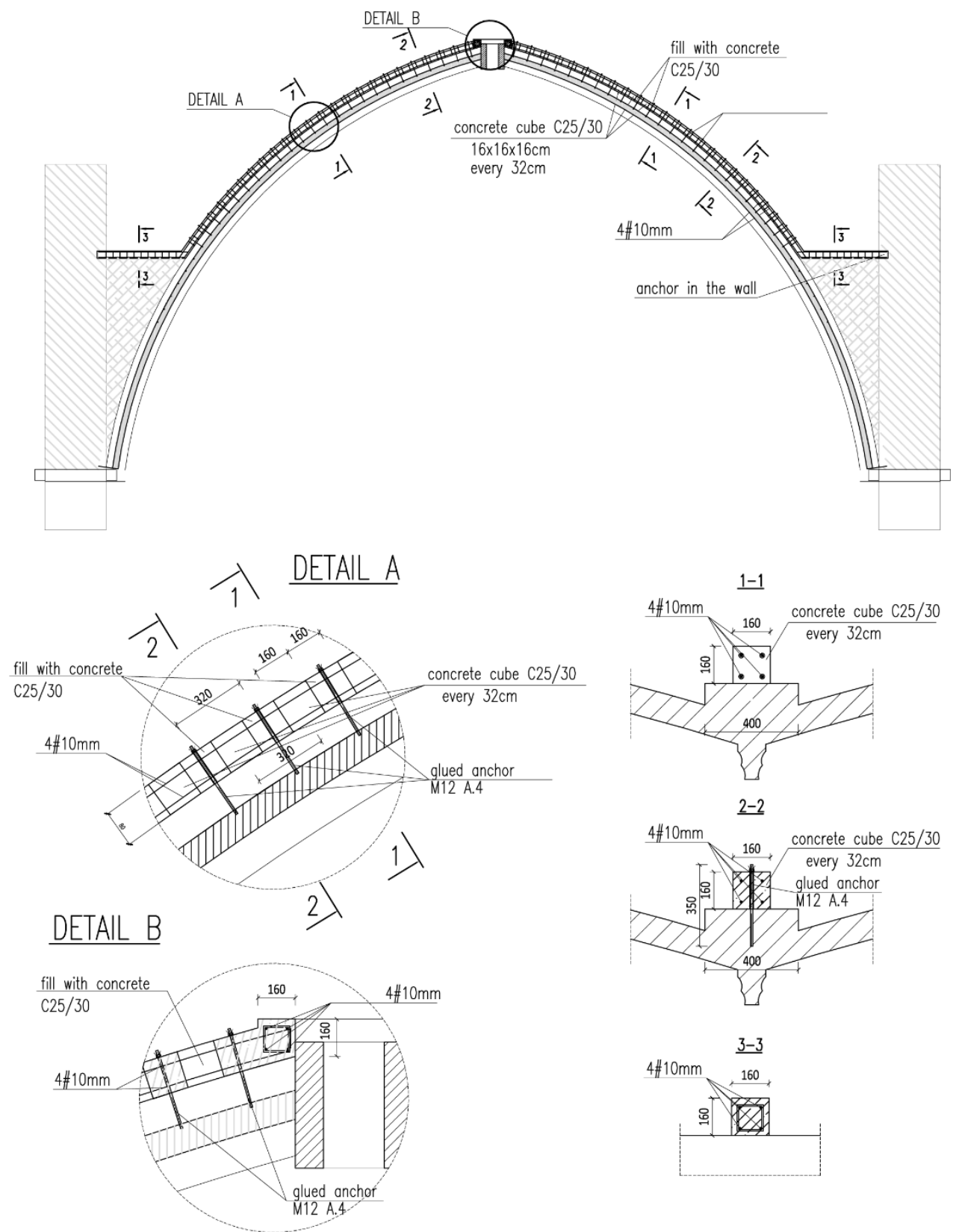

Fig. 11. Strengthening the church body with tie rods. 


\section{Repair works}

The strengthening of the church started at the beginning of September, 2018 and is planned to be completed at the end of November 2019. At the moment of completing theses works, the building will be exposed to first effects (lowering at the level of $30 \mathrm{~mm}$ ). Figs 12-15 illustrate individual stages of strengthening the church.

a)

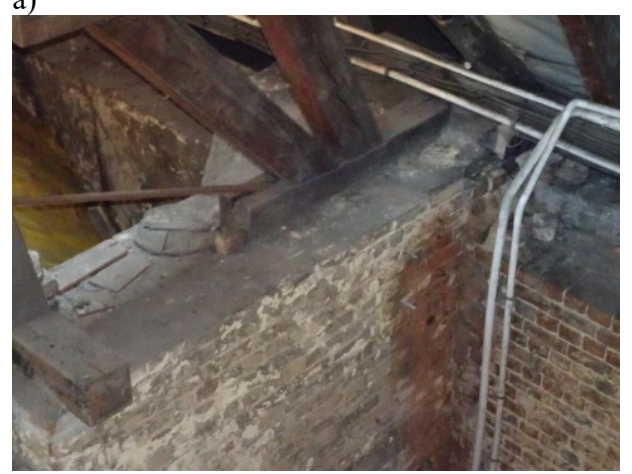

c)

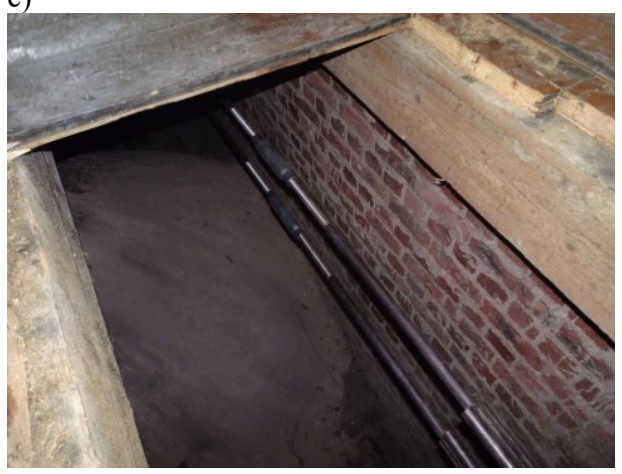

b)

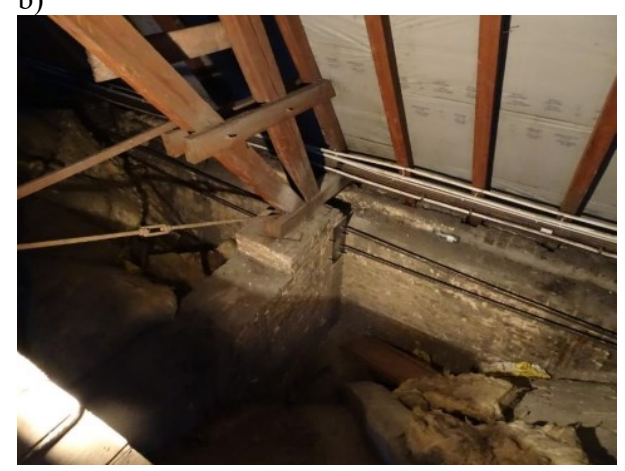

d)

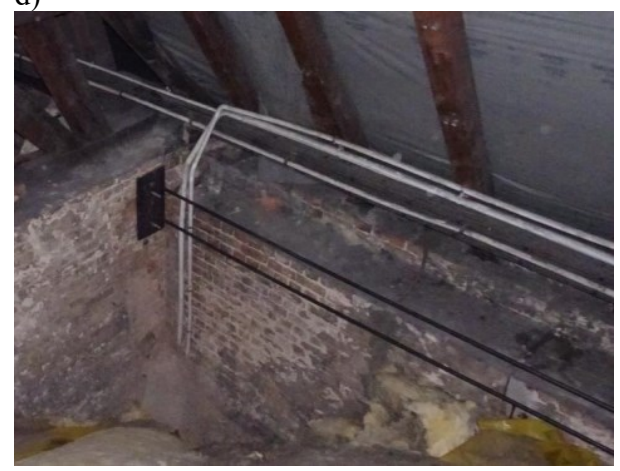

Fig. 12. Strengthening stages of the aisle with tie rods: a) making holes, b) placing tendons, c) placing stretching screws, d) stretching tendons. 


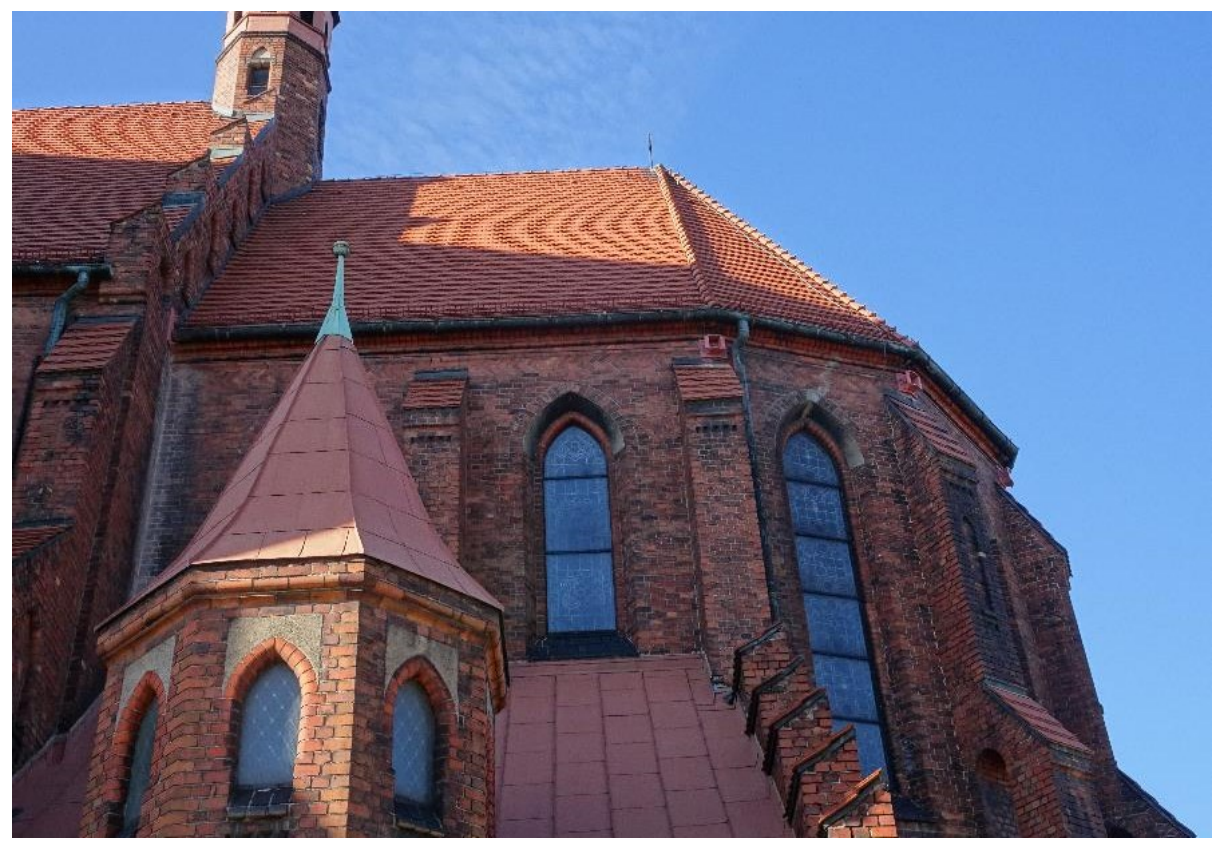

Fig. 13. A view of tendons outside the presbytery.

a)

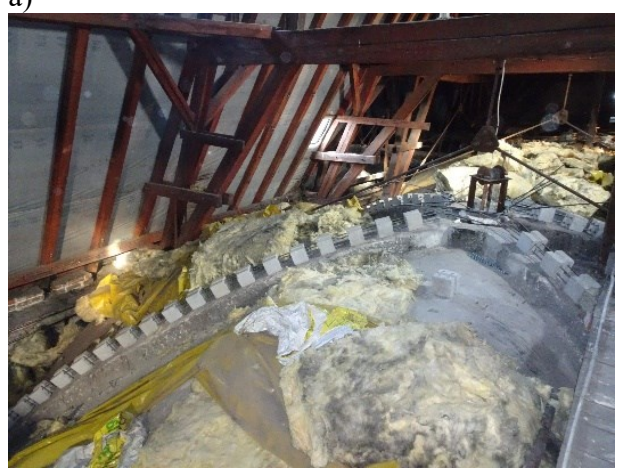

c)

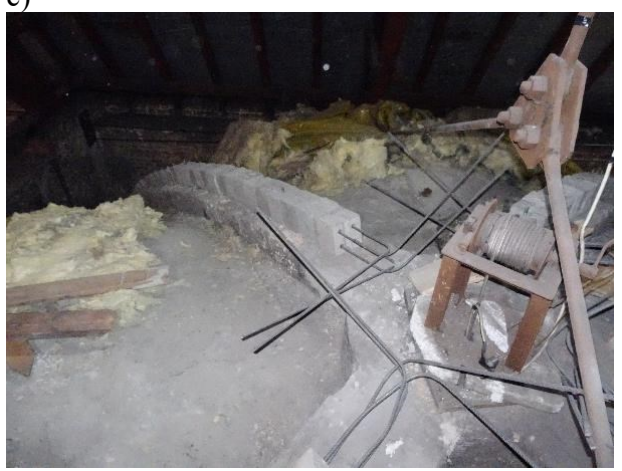

b)

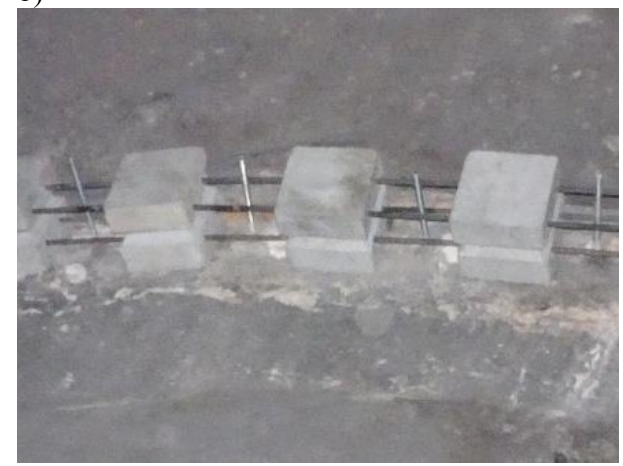

d)

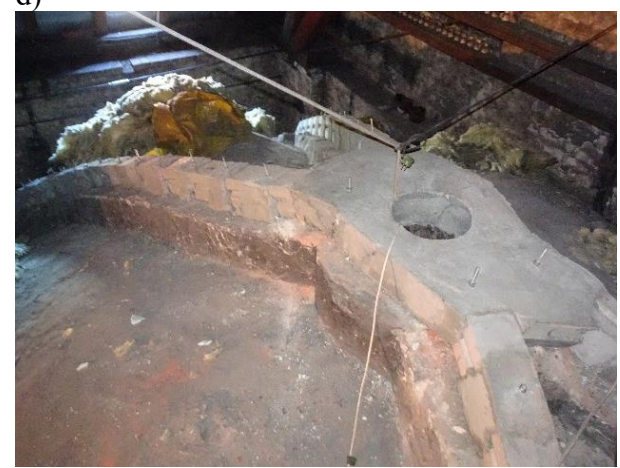

Fig. 14. Strengthening stages of ribs: a) placing cubes and reinforcement, b) assembly of anchors, c) concreting, d) concreting of keystone. 


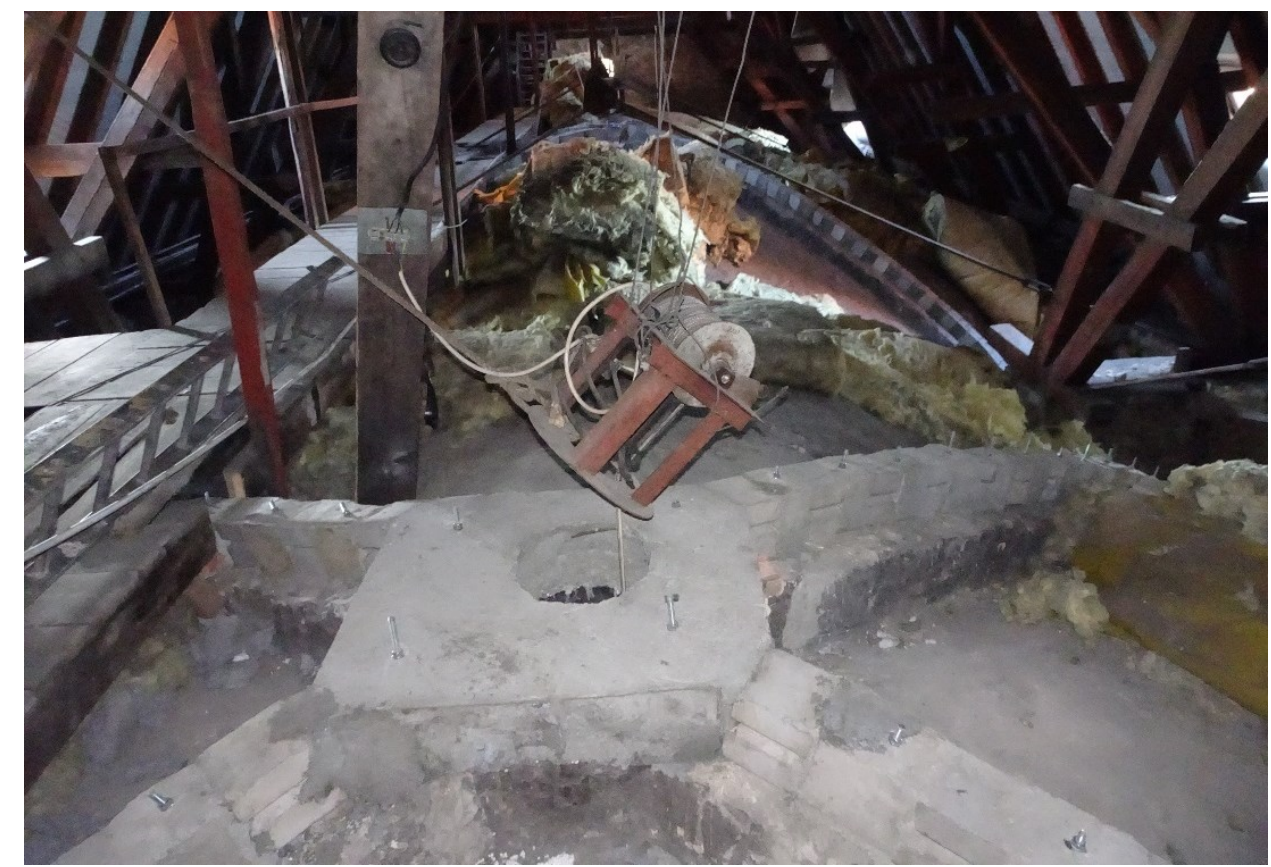

Fig. 15. A view of strengthened ribs.

\section{Summary}

This article describes strengthening works for the body of the historic church in Ruda Śląska. In the past this building was exposed to at least 22 different mining exploitation works from coal seams [3]. Impacts exerted by these exploitation works caused significant cracks in walls and vaults. Prior to another exploitation, the decision was made to strengthen walls and ribs in vaults. Walls were strengthened with steel tie rods, and ribs by suspension to new reinforced concrete ribs. New ribs had precast cube units to reduce the number of "wet" works. At the time of writing this article, the church has been already exposed to impacts that cause ground lowering at the level of $100 \mathrm{~mm}$ ). However, no damage to vaults has been observed.

\section{References}

1. M. Kawulok, Szkody górnicze w budownictwie (Instytut Techniki Budowlanej, Warsaw, 2015) [in Polish]

2. J. Kwiatek, Buildings in mining areas (Publisher of the Central Mining Institute, Katowice, 2007) [in Polish]

3. M. Kawulok, Ł. Drobiec, L. Słowik, L. Chomacki, MATEC Web of Conf. ICSF Manuscript (2019) (to be published)

4. J.A. Ledwoń, Construction in mining areas (Arkady, Warsaw, 1983) [in Polish]

5. Ł. Drobiec, Counteraction of cracking in compressed masonry with bed joint reinforcement (Publisher of the Silesian University of Technology, Gliwice, 2013) [in Polish] 